\title{
Study on the intelligent system of sports culture centers by combining machine learning with big data
}

\author{
Xiong Xiao-wei ${ }^{1}$ (D) \\ Received: 7 June 2019 / Accepted: 27 August 2019 / Published online: 21 December 2019 \\ (C) The Author(s) 2019
}

\begin{abstract}
With the vigorous development of sports, people's awareness of engaging in sports has gradually increased, and the requirements for a sports culture center have been higher. However, the service system of traditional sports cultures center is single, which cannot meet people's growing experience needs. Therefore, it is urgent for the service system of sports culture centers to move towards intellectualization. Firstly, this paper discusses the service system of traditional sports culture centers and finds that there are some problems, such as slow transmission of information, poor sharing of resources, and weak flexibility of response, which seriously affect the consumer experience of users and restrict the development of sports culture centers. Then, with the help of computer network technology, the design of intelligent system architecture of sports culture centers is completed, which makes many intelligent subsystems interconnected and interoperable, integrates information, realizes the integration of data application network, and achieves the goal of resource sharing and function upgrading. Then, based on the intelligent system, the big data platform is built with the help of big data technology, and the support vector machine-back propagation (SVM-BP) neural network composite model is used to realize the prediction of the passenger flow in the cultural center, which provides guidance for adjusting the service plan in advance, effectively coping with the peak passenger flow and improving the user experience. Finally, through empirical analysis, we know that the design of an intelligent system greatly improves the service quality of cultural centers. The research results not only achieve a significant increase in passenger flow but also provide an effective way for the service of sports culture centers to move towards intellectualization.
\end{abstract}

Keywords Sports culture center $\cdot$ Big data technology $\cdot$ Intelligent system $\cdot$ SVM-BP neural network

\section{Introduction}

The opening and service of sports and cultural centers provide people with sports convenience. People can arrange their own time for sports and exercise by prebooking or on-site booking; promote their physical and mental relaxation; and then devote themselves to learning and work. With the gradual improvement of people's living standards, the traditional sports culture center service has been unable to meet the needs of people to participate in sports [1, 2]. Intelligent construction of sports culture centers facilities has attracted extensive attention of experts in related fields. Through the establishment of an intelligent service system, including monitoring, security, intelligent communication,

Xiong Xiao-wei 6030055@jju.edu.cn

1 School of Physical Education, Jiujiang University, Jiujiang 332005, Jiangxi, China mechanical equipment, live broadcast system, and scoring equipment, it can effectively solve the problems of untimely staff service, uneven distribution of space in cultural centers, unreasonable real-time pricing, and so on, to ensure the sustainable and stable operation of sports culture centers, to maintain the balance of profits and losses of sports culture centers, and to promote the sustainable development of sports culture centers [3].

Aiming at the design of the intelligent system of sports culture centers, Liang H T [4] designs an intelligent stadium system to improve the efficiency and economic benefits of intelligent management based on the requirements of the system design of Internet of Things technology and the overall structure, system functions, and Internet of Things architecture of the system. Zhao $\mathrm{J} \mathrm{W}$ and others [5] have designed a new type of solar automatic lighting system by studying the power supply facilities in the sports culture center. The sports culture center uses sunlight during the day and stores solar energy for night lighting. The design system saves energy consumption and promotes the sustainable development of sports culture centers. Research on intelligent 
lighting control system of sports culture centers by Jin R J et al. [6] puts forward a series of measures from lighting design, lamp type selection, and installation to solve the glare problem. Peng B and others [7] used CFD numerical simulation technology to study the mechanical evacuation system, mechanical air supply system, and natural air supply system of large indoor stadiums, which provided a theoretical basis for the design of the overall smoke exhaust system. Nishioka T. et al. [8] measured and evaluated the indoor thermal environment of large dome stadiums, including temperature distribution, humidity, airflow, and outdoor weather. The strategy of using an intelligent mechanical system (such as air conditioning system) to reduce energy consumption and make full use of the space of sports culture centers was put forward. $\mathrm{Hu} \mathrm{S} \mathrm{B}$ and others [9] analyzed the current situation of a ticket-buying system based on web. By introducing virtual reality technology, the software system of virtual sports culture centers based on virtual reality technology was designed to promote the construction of intelligent sports culture centers and the improvement of benefits. Song Y [10] adopts bottom-up modeling method based on multi-agent technique and dynamically establishes an expert system model for complex adaptive decision-making of sports events through interaction between agents, which lays a theoretical foundation for bidding decision-making of large-scale individual sports projects. From this, we can see that scholars have less research on the design of the intellectualized system of the sports culture center, and they mainly focus on the intellectualized control and design of a certain system.

Therefore, this paper proposes to use computer network technology to build an intelligent system of sports culture centers. Meanwhile, the subsystem realizes data sharing through information interconnection and interoperability to provide users with humanized intelligent services. On this basis, the big data technology is used to extract and classify the passenger flow information data of cultural centers intelligently, and the support vector machine-back propagation (SVM-BP) neural network composite model based on machine learning is used to predict the passenger flow dynamically in real time, which realizes the intelligent feedback of the system and the timely formulation of the scheme, provides theoretical guidance for the intellectualized construction of the sports culture center, and has great significance for improving the service efficiency and customer satisfaction of the sports culture center.

\section{Research on the service system of traditional sports culture centers}

\subsection{Systematic analysis of traditional sports culture centers}

In recent years, many countries have invested a great deal of financial and material resources in the construction of sports and cultural center facilities. They have built various types of sports and cultural centers successively, which make great efforts to promote the extensive development of sports and improve the level of competitive sports and made brilliant achievements [11], for example, Allianz Stadium in Munich, Berlin, Werner March Stadium, Beijing National Stadium, and Wembley Stadium in London, England. These expensive sports and cultural venues not only provide a good sports environment for people but also greatly promote the exchange of different sports cultures. However, due to various factors, there are still some problems to be solved in the modern technology of large sports culture centers. The traditional service system model of sports culture centers is shown in Fig. 1.

Lack of corresponding standards in the construction of sports culture centers There is no clear standard $[12,13]$ for what kind of equipment should be equipped and planned and how to choose the specifications, forms, interface modes, and communication protocols of various equipment. As a result, each electronic equipment manufacturer and construction unit carries out their own industry standards or does not have any standards at all, which makes the equipment of electronic equipment in sports culture centers very irregular. As a result, the equipment cannot be connected. The design and manufacture of some equipment do not meet the requirements of sports competitions, and their functions are greatly reduced. It not only causes the decline of service quality of sports culture centers but also causes the waste of resources of sports culture centers to a certain extent.

The service systems are independent and inefficient At present, most of the sports culture center service systems adopt $\mathrm{C} / \mathrm{S}$ structure. In the application process, both client and server need to install specific application software systems. For different operating systems, corresponding software systems need to be developed. With the updating of products, it is difficult to adapt to the simultaneous use of users in a hundred-scale LAN. Moreover, they lack necessary connections and cannot be compatible with each other. And in the actual service, the service personnel who manage each system lack corresponding response, the allocation of venue resources is also unreasonable, flexibility is poor, the sports and cultural center is difficult to manage uniformly, resulting in waste of human resources, and high utilization rate of the sports and cultural center is difficult to achieve [14, 15].

To sum up, the traditional sports culture center service system not only is inefficient but also causes a certain degree of waste of manpower and site resources. The main reasons for these problems are as follows: slow data transmission of various services, poor sharing of resources, and not fully tapping the large amount of data generated by sports and cultural centers, so it cannot be adjusted in time. In order to avoid these problems, it is necessary to fully tap the mass data generated 
Fig. 1 Service system model of sports culture centers

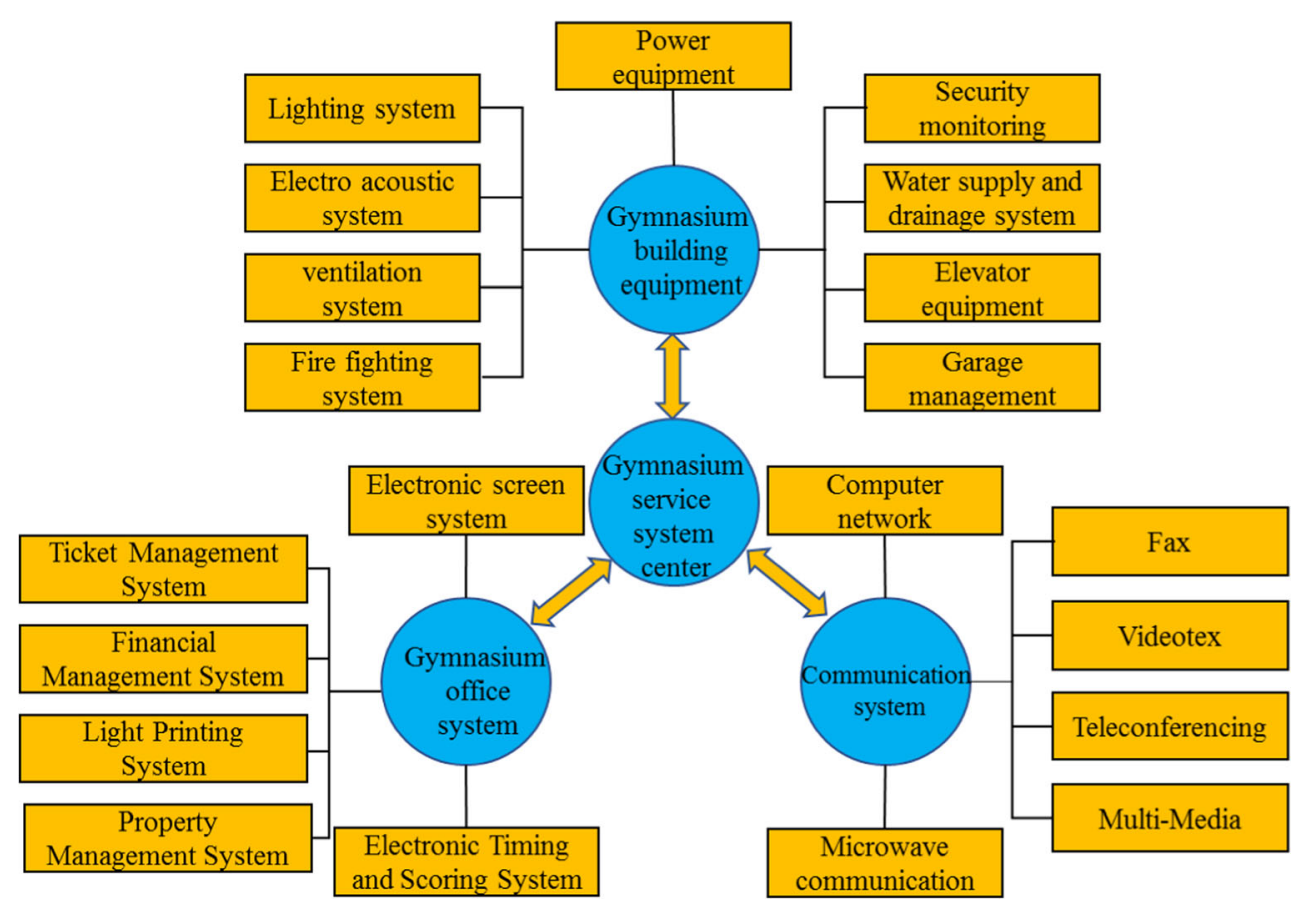

by a sports culture center, get the inherent rules of each service system, and adjust it in time by sharing. Therefore, it is necessary to design the service system of sports culture centers intelligently with the help of big data technology.

\subsection{Analysis of service ability index of sports culture centers}

The passenger flow of sports culture centers depends on the service ability of sports culture centers. The simultaneity of service production and consumption means that service process is an interactive process between service personnel and customers [16]. Employees with high service skills can bring high-quality service, and high-quality service can bring high satisfaction of customers. This high satisfaction of customers is the size of service ability of sports culture centers [17].

In addition, the sports culture center is not only a service place or service resources but also a service organization. The management responsibility of sports culture centers is to transform the space of sports culture centers into service products to provide customers with consumption so as to realize its service ability. Whether the service ability of sports culture centers can be truly realized depends on the following important links:

(1) Cultural center facilities: Sports and cultural centers have the conditions to serve the public. In the process of forming the service ability of sports culture centers, we need to invest a lot of tangible and intangible resources such as manpower, material and financial resources, such as the construction, facilities, equipment, and service personnel, and system and culture of sports culture centers. The simultaneity of service production and consumption determines that the customer is the object of service as well as the main body. At the same time, the cost of resource acquisition also affects the service ability of sports culture centers. Therefore, in order to truly realize the service ability of sports culture centers, we must strengthen the process of construction and management of service resources of sports culture centers and the allocation and integration of management enterprises of sports culture center halls [18].

(2) Operation and management: The sports and cultural center management can realize the needs of the service object. The sports and cultural center management is required to actively obtain customer demand information and customer's consumption information, according to the standards required by customers and the multifunctional characteristics of sports and cultural center space to develop service standards and standards.

(3) Service innovation: Different customers have different demands for services. Therefore, sports culture centers should reflect differences in the process of service production according to the special needs of different customers. The business enterprises of sports culture centers have to face not only social, governmental, personal, and public consumers but also industry competition, which requires the managers of sports culture centers not only to integrate unity and flexibility in the formulation of their service standards but also to carry out service innovation [19]. 
In addition, consumer demand for sports services in sports and cultural centers has changed in periodicity, and there is a great difference between the peak period and the low period. According to the demand characteristics and the space utilization characteristics of the sports and cultural center, the management of the sports and cultural center can adjust the working hours of the service personnel to meet the changing needs of customers in periodicity, that is, the working hours of the service personnel are fully consistent with the consumption time of consumers so as to better and fully enhance the service capacity of the sports and cultural center [20].

To sum up, the service ability of stadiums is based on excellent service staff, innovation as the source, facilities as the basis, and customers as the support. Therefore, this paper constructs the influencing factors system of passenger flow in sports culture centers from four aspects: human resources, sports culture center facilities, time, and consumers, as shown in Fig. 2.

Human resources refer to the multi-functional use of stadium space by stadium managers to provide consumers with consumption, mainly including the brand effect of cultural centers, service standards and standards of cultural centers, government policy support, and service innovation. Facilities of cultural centers can be divided into facilities and facilities environment. Facilities are part of stadium resources, which directly affect the service ability of sports culture centers. They mainly include the following: ancillary service facilities of cultural centers, geographical environment, architectural characteristics of cultural centers, and surrounding economic environment. Time refers to the opening time of sports culture centers and the time spent by customers. It is an important factor to regulate the service ability of sports culture centers. This paper analyzes the influence of time on the service ability of sports culture centers from four angles: the opening time of sports culture centers, the waiting time for customers to buy tickets, the waiting time for consumers to make reservations, and the working time of service personnel. Consumers refer to the people who come to the sports culture center to consume. As a kind of input resources of their stadium service ability, they mainly consider the quality of consumers, consumption experience, consumption motivation, and consumption grade.

\section{Intelligent system design of sports culture centers based on big data}

\subsection{Big data technology}

Intelligent system design based on big data is the core of building intelligent sports culture centers. Big data plays a very important role as the database. Although big data has been applied in many fields, many scholars have disputed the understanding of big data. McKinsey believes that big data is a data set and he pointed out: "Big data is a data set that exceeds the capabilities of typical database software tools for collection, storage, management, and analysis. [21]." There are also scholars who define big data from a technical perspective. British scholar Victor Meyer Schonberg defines big data as a shortcut that does not use stochastic analysis but uses all
Fig. 2 Influencing factors of passenger flow in sports culture centers

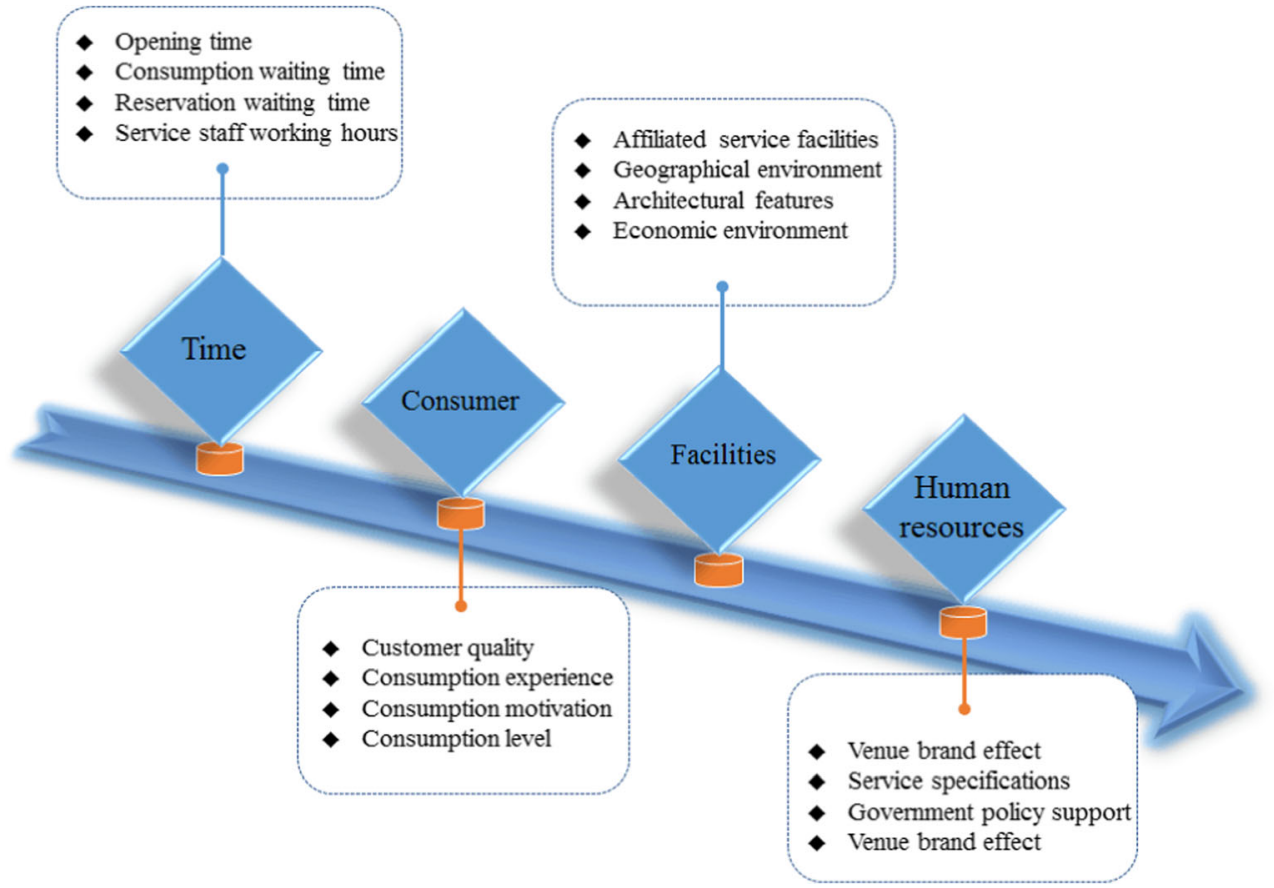


data for analysis and processing [22]. Three key features are involved in the definition of big data [23]: First, massive data has exceeded the processing power of common typical databases or hardware and software environments. Therefore, big data is not suitable for centralized data processing and generally uses distributed data storage instead. Second, these data sets include both structured data and massive unstructured data and semi-structured data such as text, images, sounds, and web pages. Third, these massive amounts of data require technical processing to be effective. Therefore, big data often complements information technology. In the construction of intelligent sports culture centers, the sports culture center is taken as the resource object, and its historical operation data are monitored and analyzed by using big data technology. In this process, the intelligent management and control of sports culture centers is realized by using the data of scheme dispatching automation, information collection and user feedback, data mining, parallel computing, and decision tree technology.

The key to the application of big data technology is the integration of IT and "business." In this paper, it refers to "Internet + sports culture center" [24]. The new intelligent sports culture center is a combination of network, digital, and intelligent features. In other words, it is the use of Internet technology to realize the mutual perception between the operators and users of sports culture centers, the service personnel of sports culture centers, sports equipment, and venues. In this process, a huge information network will be formed and a large amount of data will be generated in real time. At the same time, with the help of big data processing technology, the hidden value in massive data is deeply explored to improve the problems existing in the operation of the cultural center, thus providing intelligent service and management platform for customers and cultural center operators.

\subsection{Overall architecture design of the intelligent system of sports culture centers}

The main purpose of the sports culture center is to host competitions and provide daily sports services to customers. The cultural center is large due to its various events. The cultural center usually has relatively few managers. During the event, the passenger flow is large, and the staff will be temporarily maintained and managed. The cultural center's intelligent facilities have huge investment funds and high operating costs, which has led many sports and cultural centers to barely maintain breakeven. A standard intelligent sports culture center requires a large amount of equipment such as security, monitoring, scoring, intelligent communication, and mechanical facilities, which requires huge equipment purchase costs and labor costs. Therefore, it is required to carefully consider the characteristics of the sports culture center itself in design and minimize the investment in intelligent facilities [25]. With the continuous improvement of the audience's appreciation level, the sports culture center should manage and improve the sound quality. The intelligent system of the sports culture center is different from other office building intelligent systems. Due to the characteristics of the cultural center competition, the system pays more attention to the design of subsystems related to the competition [26], such as integrated wiring, scoring system, live broadcast system, data networks, communication systems, and venue lighting. The most important of these is the competition integrated pipeline system, which provides various wiring for the competition, including the abovementioned scoring system, live broadcast system, broadcast system, performance registration and inquiry, news reports, and other subintelligent systems required for various intelligent pipelines. The main purpose of building an intelligent cultural center is to provide customers with access to various services and training facilities in the cultural center. The overall intelligent architecture design of the sports culture center is shown in Fig. 3.

\subsubsection{Intelligent monitoring system}

Building automation system Based on modern computer technology, control technology, network technology, and graphic image processing technology, centralized management and automatic monitoring of all electromechanical equipment are realized to ensure the safe operation of all electromechanical equipment in the sports culture center and improve the staff's comfort and productivity in the sports culture center, as well as keep equipment running at low cost. Once the equipment fails, the system can know in time when and where the fault occurs, and the accident is eliminated in the bud.

Security system The security system consists of a monitoring system, access control, and alarm system and includes monitoring points at the main entrances and exits, important passages, guard posts, and security checkpoints. The access control system uses an embedded CPU identification card [27]. The alarm system sets up an infrared alarm device at the important entrances, passages, computer rooms, and office buildings in the hall and realizes linkage with nearby surveillance cameras. The cultural center security system requires system integration of the security subsystems, and the independent subsystems are integrated into one system through system integration software.

\subsubsection{Communication network system}

For intelligent systems, "wiring is the foundation, the network is the platform, and the application is the core." The network system should provide an information network platform for event management and cultural center integrated operation services, which are generally divided into intranet and 


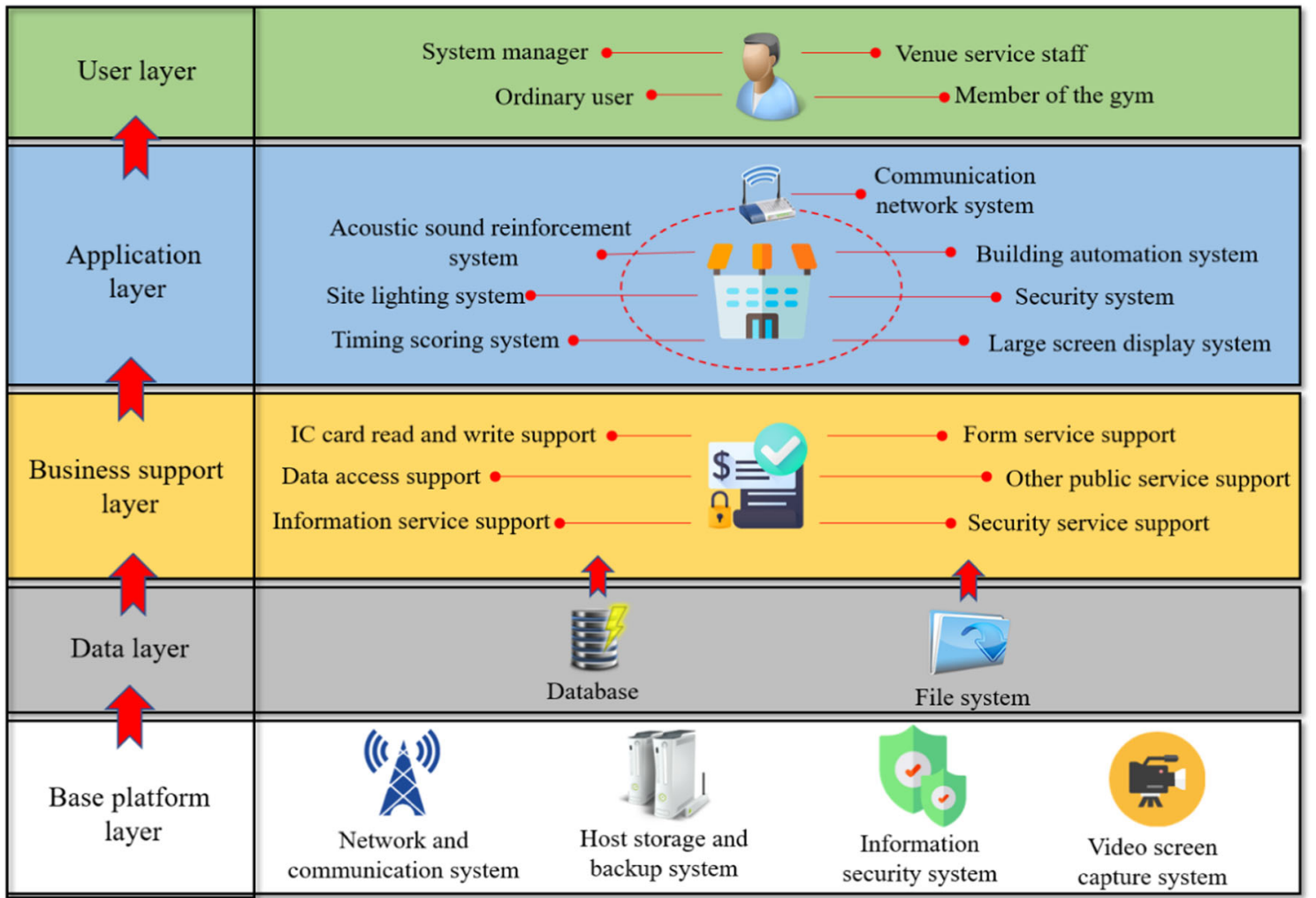

Fig. 3 The overall architecture design of the stadium intelligent system

extranet. The intranet is responsible for data processing related to events and athletes. The external network is responsible for the office of the cultural center and communication with the outside world [28]. The external network cannot modify the internal network data. The computer network system has great responsibility in the entire intelligent system and can share information with multiple platforms, providing necessary conditions for the integrated subsystem. In the specific design, the horizontal cable uses Category 6 UTP twisted pair, and the information point adopts 6 types of information modules. For important performance review and playback, optical communication is used to ensure the integrity of information transmission. At the same time, the entire network should have the function of setting up wireless network hotspots. The audience, referees, reporters, etc. can connect the mobile Internet devices that they carry with them to the wireless network to realize network office. The wireless network should set up a staff account and an open account for the audience to avoid inconvenience to the daily work of the cultural center. The servers used at the competition site can be assembled and tested by specialists before the game.

\subsubsection{Event service subsystem}

Large-screen display system The main function of the largescreen display system is to publish various news of the cultural center and display the dynamics of sports events, the situation of each team and competitors, the results of various competitions, rankings and real-time scores, the live broadcast of the TV on the stadium, etc. At the same time, it is also possible to broadcast advertising information and play various commercial contents such as videos, animations, texts, and overlays. The large-screen display system is the basic subsystem of the cultural center's information services for competition, training, and large-scale social activities. It will directly affect the quality of the cultural center infrastructure.

Venue lighting system The lighting system of the sports culture center is required to satisfy the audience's good viewing effect and must also ensure the lighting requirements for referees, athletes' competitions, and TV broadcasts. Depending on the sport, the lighting control system can be flexibly adjusted to suit the needs of various sports and activities. Therefore, the lighting of the sports culture center should have a high-quality lighting environment, such as suitable uniform illumination and brightness, ideal light color and color rendering, good three-dimensionality, and no glare.

Acoustic sound reinforcement system The sound system of the sports culture center is mainly to meet the requirements of the language reinforcement of sports competitions. In addition, it can undertake some large-scale cultural performances. In terms of use function, it is different from other hall sound reinforcement, and it is different from the theater sound reinforcement. It has its particularity. In addition, the sound 
system ensures the clarity of the language is high, the sound quality is soft, the sound pressure coverage is uniform, and the power of the equipment is required to be large and leave a margin. The acoustic characteristics of the building in the sports culture center are generally poor, mainly due to its large size and long reverberation time. Therefore, special consideration should be given to acoustic decoration during the decoration stage so that the cultural center guarantees good acoustic characteristics.

Timekeeping scoring system The timekeeping scoring system is the basic technical facility that is activated when the event is held in the sports culture center. According to the different events, the timing and scoring equipment used is not the same. The specific plan should be designed according to the competition rules of each project and the operational requirements of the stadium. The main function of the system is to obtain the athlete's performance scores reliably and accurately. At the same time, the relevant information is displayed in time by the large-screen equipment so that the guests, judges, and spectators present can know the latest game information in time.

\subsection{Building a big data platform}

The development of Internet technology has greatly promoted the sports culture center to move towards intelligence. It has largely transformed the sports center service with scattered, lagging, and error into centralized, efficient, and precise. This not only ensures the fairness and justice of sports events but also greatly satisfies the user's consumption experience, laying a foundation for further promoting the development of sports culture centers [29]. In addition, with the application of Internet technology and the investment of advanced monitoring equipment, the sports culture center generates a large amount of data in real time during normal operation. These data are of great significance for predicting changes in the traffic volume of the sports culture center. In the past, these data could not be collected and processed effectively. Nowadays, advanced detection equipment can complete the data collection in the first time and then realize the rapid transmission of data by means of the communication network system. Finally, the data center performs preliminary processing and storage of data from multiple detection nodes, builds a big data platform, and lays a data foundation for the next step of data mining. The construction process of the big data platform is shown in Fig. 4.

\section{Passenger flow forecast model of sports culture centers based on big data platform}

Through the construction of an intelligent system and a big data platform for the sports culture center, the daily passenger flow of the sports culture center is deeply stored and the dynamic extraction of data is realized. The daily, monthly, and quarterly passenger flow of the sports culture center is effectively predicted based on improved SVM intelligent algorithm. Combined with the development trend of passenger flow, timely feedback allows the staff to provide mitigation measures for the passenger flow control, cultural center service, and equipment rental of the sports culture center. The improvement plan is formulated to effectively prevent the problems of skyrocketing passenger flow and untimely service of the sports culture center, reduce unnecessary economic and space investment within a reliable time, and achieve profit for the sports culture center to the greatest effect. Therefore, we construct a sports culture center passenger flow forecast model based on big data platform, which plays an important role in the development of its business model.

\subsection{Construction of passenger flow forecast model for sports culture centers based on SVM}

In the big data platform, information data on the passenger flow of the sports culture center will be intelligently classified, extracted, and analyzed. At the same time, a prediction model of passenger flow based on support vector machine (SVM) is constructed. By inputting the data of various impact indicators and training and learning the data, the development trend of passenger flow of the sports culture center in time series can be better predicted. SVM was first proposed by Corinna Cortes and Vapnik in 1995 [30]. It has unique advantages in solving nonlinear and high-dimensional pattern recognition. Its regression methods are divided into linear regression and nonlinear regression. On the whole, a series of parameters are estimated and predicted according to certain rules and standards based on given training samples. To some extent, it breaks through the limitations of traditional linear conditions compared with statistical regression analysis. And it has higher scale universality and excellence.

The regression principle of SVM is to assume that the initial training sample set is $T=\left\{\left(x_{i}, y_{i}\right), i=1,2, \cdots, N\right\}, x_{i} \in$ $R^{n}, y_{i} \in R$, and $N$ represents the training sample size. The input sample data is mapped into a high-dimensional feature space by nonlinear mapping, and then a regression equation $f(x)$ is constructed.

$f(x)=W^{T} \varphi(x)+b$

In the formula, $W$ is the weight vector and $b$ is the offset. The relaxation variables $k_{i}$ and $k_{i}^{*}$ are introduced on this basis, and the optimization problems are determined as follows:

$\min \frac{1}{2} W^{2}+C \sum_{i=1}^{N}\left(k_{i}+k_{i}^{*}\right)$ 


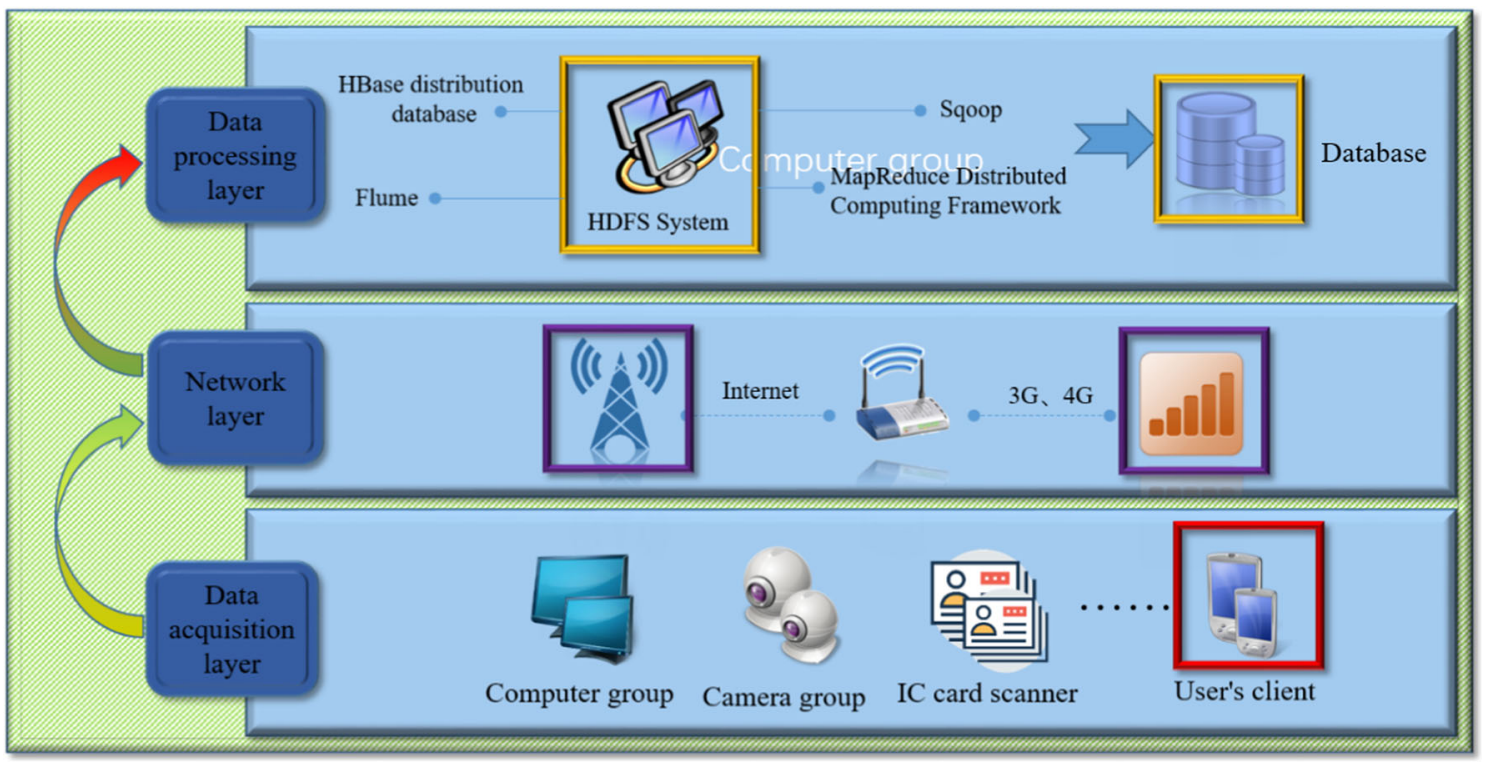

Fig. 4 Establishment of big data platform based on intelligent venues

$$
\begin{aligned}
& \text { s.t. } y_{i}-\left(W^{T} \varphi(x)+b\right) \leq \varepsilon+k_{i} \\
& \left(W^{T} \varphi(x)+b\right)-y_{i} \leq \varepsilon+k_{i}^{*}, k_{i}, k_{i}^{*} \geq 0
\end{aligned}
$$

In the formula, $C$ is a penalty factor; $k_{i}$ and $k_{i}^{*}$ are nonnegative relaxation variables. At this time, Lagrange multiplier is introduced to change formula (2) into:

$$
\begin{aligned}
& \max \sum_{i=1}^{N} a_{i}-\frac{1}{2} \sum_{i=1}^{N} \sum_{j=1}^{N} a_{i} a_{j} \varphi\left(x_{i}\right) y_{i} y_{j} \\
& \text { s.t. } \quad \sum_{i=1}^{N} a_{i} y_{i}=0 \quad 0 \leq a_{i} \leq C
\end{aligned}
$$

The solution of the quadratic programming problem is the same as that of the dual problem. The optimal solution is determined as $a^{*}=\left\{a_{1}^{*}, a_{2}^{*}, \cdots a_{N}^{*}\right\}^{T}$, and then $W^{*}$ and $b^{*}$ are calculated. The regression equation thus obtained is:

$f(x)=\sum_{i=1}^{N} \sum_{j=1}^{N} a_{i}^{*} y_{i} \varphi\left(x_{i}\right) \varphi\left(x_{j}\right)+b^{*}$

In order to avoid problems caused by too high dimension, the stone function is usually used to replace the formula $\varphi\left(x_{i}\right) \varphi\left(x_{j}\right)$. Common stone functions include linear function, polynomial function, sigmoid function, and RBF function [31, 32], and their function forms are shown in Table 1.

The data affecting the passenger flow of the sports culture center are extracted from the data platform as initial samples and input into the model for training and learning to realize real-time prediction of passenger flow. Although SVM has certain advantages in the prediction process, due to certain limitations of the stone function itself, the prediction results of single stone function have certain deviation. In order to better condense the advantages of stone function and complement the respective limitations of stone function, SVM is improved to reduce the error between prediction results and real values.

\subsection{Improvement of passenger flow forecast model}

In order to further improve the prediction model based on SVM, this paper constructs a compound model based on SVM-BP neural network to predict the passenger flow of sports culture centers. The prediction output result under the single stone function of SVM [33] is taken as the initial input value of the neural network, and continuous feedback is used to reduce the error limit and improve the prediction accuracy. At the same time, due to the randomness of the initial weights and thresholds of the BP neural network. The training process of the network often falls into local optimization and the fitness decreases. Therefore, the genetic algorithm is used to optimize the BP neural network on this basis [34]. The core link of the optimization process is to take the individual in the initial sample as the initial weight and threshold of BP neural network and the initial error of the obtained individual as the fitness value. After selection, crossover, mutation, and other operations, the optimized weight and threshold are obtained [35].

The fitness function uses the sample mean square error to estimate the quality of the solution, and the calculation formula is:

$$
\begin{aligned}
& \mathrm{MSE}=\frac{1}{N} \sum_{i=1}^{N}\left(f\left(x_{i}\right)-y_{i}^{*}\right)^{2} \\
& F(w, \sigma)=\left\{\begin{array}{c}
\frac{1}{\mathrm{MSE}}, \mathrm{MSE} \neq 0 \\
F_{\text {best }}+1, \mathrm{MSE}=0
\end{array}\right.
\end{aligned}
$$


Table 1 Types of kernel functions

\begin{tabular}{ll}
\hline Function types & Formula \\
\hline Linear & $k\left(x_{i}, x_{j}\right)=x_{i} \cdot x_{j}$ \\
Polynomial & $k\left(x_{i}, x_{j}\right)=\left(\left(x_{i} \cdot x_{j}\right)+1\right)^{d}$ \\
Sigmoid & $k\left(x_{i}, x_{j}\right)=\tanh \left(\eta<x_{i}, x_{j}>+\theta\right)$ \\
RBF & $k\left(x_{i}, x_{j}\right)=\exp \left(\frac{-\left(x_{i}-x_{j}\right)^{2}}{\sigma^{2}}\right), \sigma$ is the bandwidth \\
\hline
\end{tabular}

In formula (8), $N$ is a set of training samples, $f\left(x_{i}\right)$ is the predicted value of passenger flow, and $y_{i}^{*}$ is the actual value of passenger flow. In formula (9), $F_{\text {best }}$ denotes the initial weights and threshold $(w, \sigma)$ for finding the optimal combination of parameters. The roulette method is adopted in the selection operation, and the selection probability of each individual is as follows:

$p_{i}=\frac{J_{i}}{\sum_{i=1}^{n} f_{i}}$

In the BP neural network, the formula of input and output for each layer is:

net $=x_{1} w_{1}+x_{2} w_{2}+\cdots+x_{n} w_{n}$

$y=f($ net $)$

In the formula, $w_{1}, w_{2}, \cdots, w_{n}$ is the weight and $f(\cdot)$ is the activation function. The commonly used activation functions are log-sigmoid function, tan-sigmoid function, etc. The genetic optimized BP neural network is a multi-layer feedforward network. It uses the algorithm of error back propagation to train and continuously revise the weights of each connecting layer and obtains the minimum error limit of predicted value and actual value. Finally, the predicted output value with high reliability is obtained $[36,37]$.

Therefore, the construction of the combined model from single stone function prediction to BP network prediction based on stone prediction results is completed. The model realizes the large deviation of the original single stone function prediction results, and the error is controlled within a certain range through the secondary input of the prediction results. The construction of the passenger flow prediction model of sports culture centers based on big data platform is shown in Fig. 5.

The model can be used to scientifically predict and analyze the development trend of passenger flow peak based on big data platform data. At the same time, the results of the corresponding predicted data can be timely fed back to the staff of the sports culture center so as to realize the advance notice and notification to the relevant staff. It is beneficial to the improvement of the service plan implemented by the relevant staff, to effectively deal with the passenger flow peak and to improve the overall customer service quality.

\section{Example analysis}

The intellectualized system of sports culture centers is the brain and nerve of modern large-scale sports culture centers, and it is an important guarantee for the smooth progress of sports events. On the one hand, a complete GIS can make sports events fairer and more accurate and improve the efficiency of referees greatly. On the other hand, it can improve the viewing degree of sports competitions and increase the social benefits of sports culture centers and sports competitions. In this paper, a daily passenger flow forecasting algorithm based on big data and a bus arrival time forecasting algorithm based on big data are designed by using SVM-BP neural network composite model. Therefore, two kinds of codes of the two algorithms are designed in the experiment. One is the preprocessing program of the standalone version, and the other is the program after Map Reduce of the processing algorithm. The stand-alone version of the program uses the traditional data processing method and runs on one node to complete the processing. The Map Reduce-based program uses parallel processing method and processes on multiple nodes in parallel. In order to compare the effect and performance of the algorithm and the impact of big data sets on the performance of the algorithm, the following experiments are designed.

As shown in Figs. 6 and 7, it can be seen that the economic benefits of sports culture centers do not increase with the increase of the number of people. The reason may be that the maintenance costs of sports culture centers will increase due to seasonal changes. Figures 8 and 9 are the training process and error analysis, respectively. From the figure, we can see that the set error limit is reached at step 713, and the training ends at step 1200, which exceeds the set error level. The error is basically stable at $0.5 \times 10^{-5}$. The running time of the improved SVM model is about $400 \mathrm{~ms}$, which is closely related to the performance of the equipment. The improved SVM model will be embedded in the network system to provide an information network platform for event management and venue-integrated operation services. Computer network system has a great responsibility in the whole intelligent system. It can share information on multiple platforms and provide necessary conditions for integrated subsystems. Using a well-trained network, the forecast of human flow and economic benefits is shown in Fig. 11.

Figure 10 predicts the flow of people and expected benefits in the next 10 days. From the figure, we can see that the intelligent design of sports culture centers is conducive to improving people's satisfaction with sports culture centers, and the flow of people will increase. Compared with the traditional SVM algorithm, the improved SVM-BP model has significantly improved the prediction accuracy. From Fig. 11, 




Fig. 5 Forecast model of stadium passenger flow based on big data platform

it can be seen that the ninth prediction results are quite different from the actual results. This is due to the increase in the flow of people, which results in a significant increase in the cost of intelligent system evaluation of sports culture centers. Therefore, the benefits of sports culture centers do not exactly correspond to the flow of people.
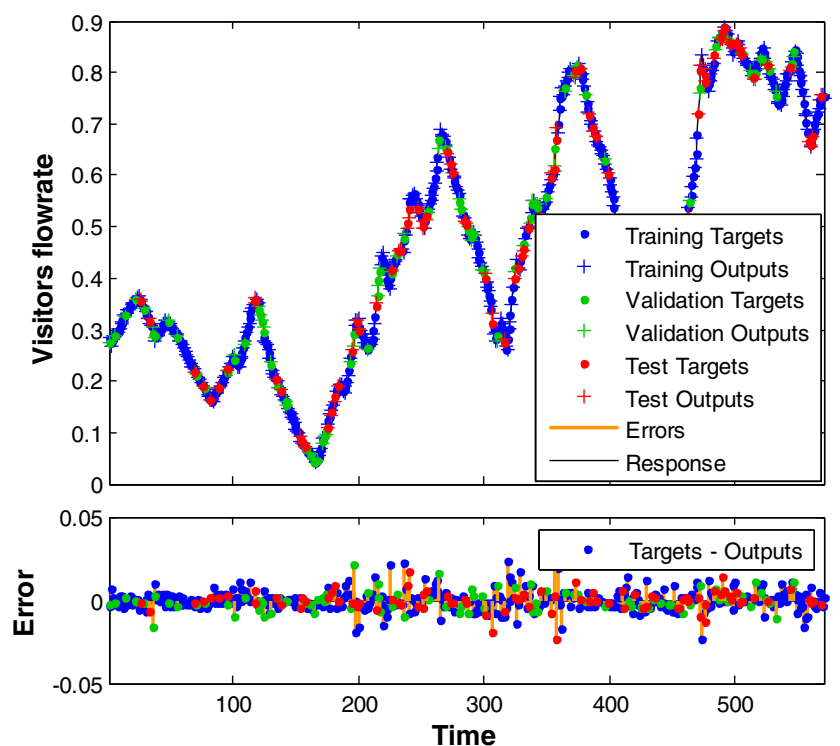

Fig. 6 Prediction of crowd flow in sports culture centers based on improved SVM model

\section{Conclusion}

With the vigorous development of China's sports industry, the demand of sports competitions for the intelligent system of sports culture centers is getting higher and higher. This paper introduces the design of an intellectualized system of sports

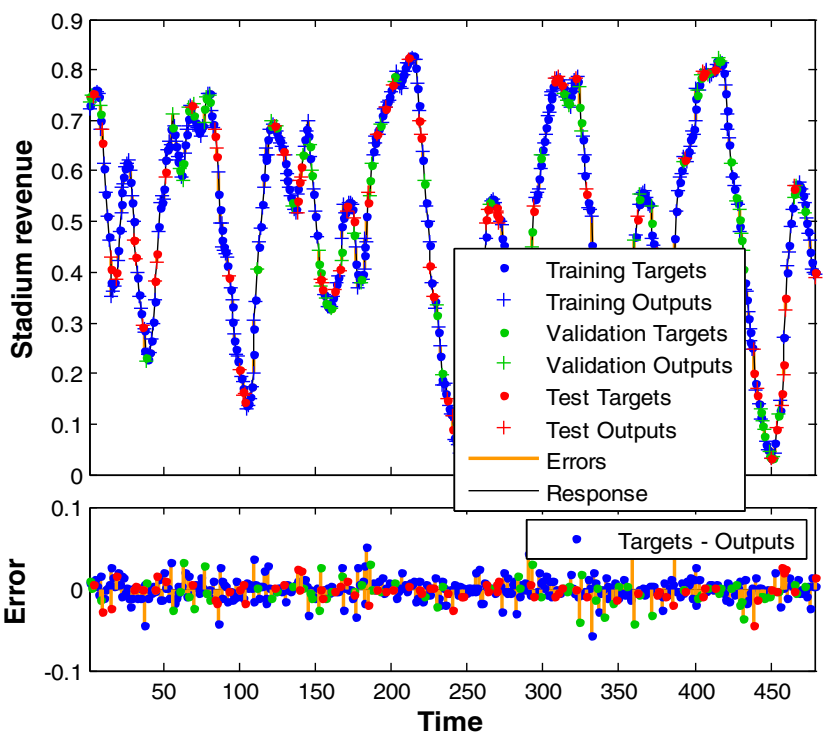

Fig. 7 The improved SVM model predicts the profit of sports culture centers 


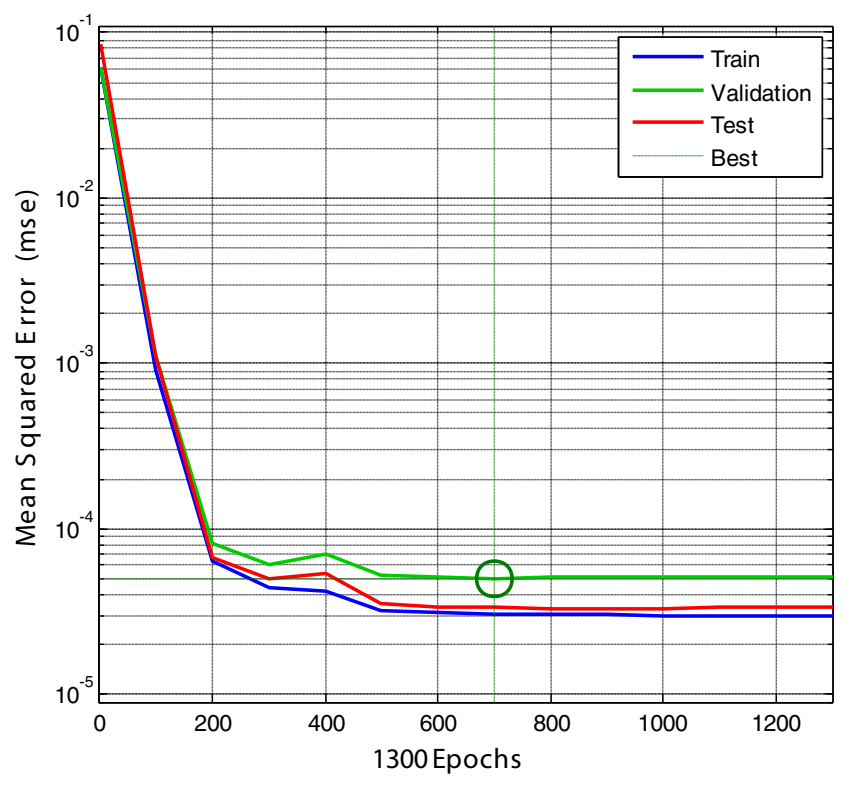

Fig. 8 The process of SVM-BP model prediction

culture centers for big data and the characteristics of an intellectualized system of sports culture centers. The realization methods of each intelligent subsystem are analyzed in order to help the intelligent design of sports culture centers. The prediction model based on SVM is improved, and the prediction accuracy is improved. Finally, an example is given to verify the model. This paper mainly makes some contributions:

(1) The disadvantages of the traditional service system model of sports culture centers are analyzed. A new evaluation index system of the service system of intelligent

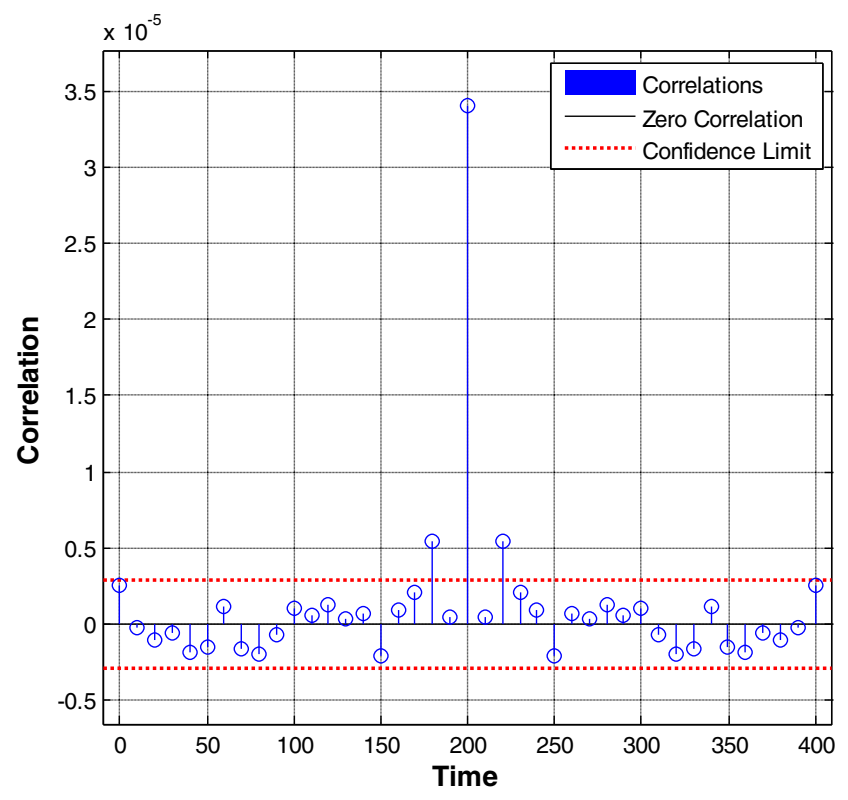

Fig. 9 Prediction error analysis of improved SVM model

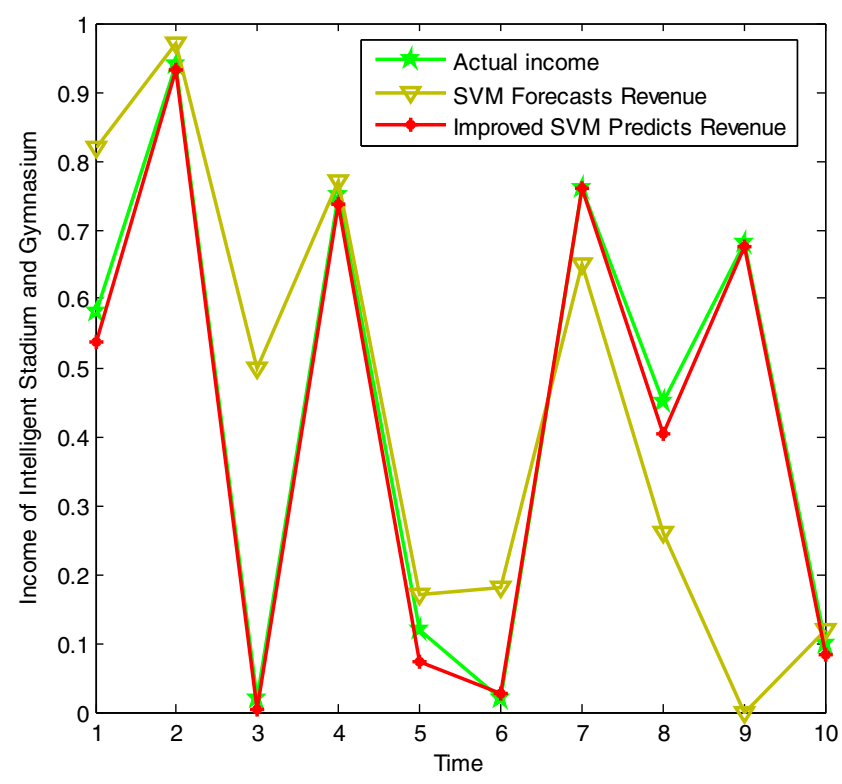

Fig. 11 Comparison of SVM model and traditional SVM sports culture center income forecast

sports culture centers is established by using big data technology. Then, the innovative design of the intelligent system of sports culture centers is carried out for big data.

(2) This paper constructs a composite model based on SVMBP neural network to forecast the passenger flow of sports culture centers. Through continuous feedback, it reduces the error limit and improves the prediction accuracy, which is verified by an example.

(3) The simulation results show that the income curve of sports culture centers is not entirely consistent with the flow of people. This is due to the increase of the flow of

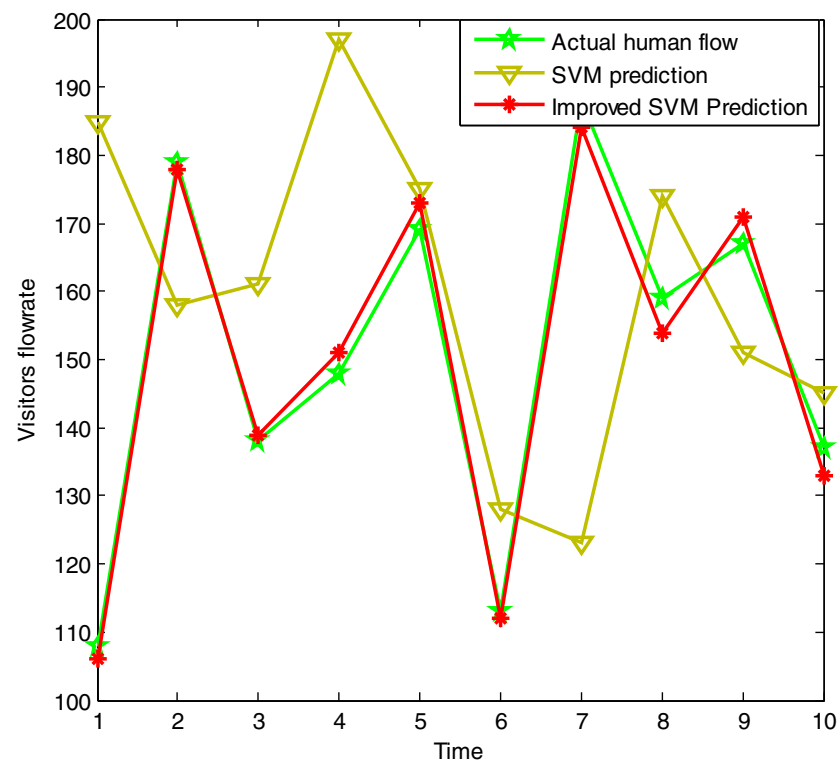

Fig. 10 Comparison of SVM-BP model and traditional SVM traffic forecast 
people, which increases the cost of the intelligent service system of sports culture centers.

(4) This paper only designs and simulates the intelligent service of a large sports cultural center, which is not suitable for the sports cultural center with less passenger flow. The construction of intelligent sports venues requires that the designers and builders not only understand the intelligent network system but also understand the particularity of the stadium itself, combining computer technology and reality. Only in this way can we design a place that meets the requirements of the competition, and it can be improved in the future research.

Open Access This article is licensed under a Creative Commons Attribution 4.0 International License, which permits use, sharing, adaptation, distribution and reproduction in any medium or format, as long as you give appropriate credit to the original author(s) and the source, provide a link to the Creative Commons licence, and indicate if changes were made. The images or other third party material in this article are included in the article's Creative Commons licence, unless indicated otherwise in a credit line to the material. If material is not included in the article's Creative Commons licence and your intended use is not permitted by statutory regulation or exceeds the permitted use, you will need to obtain permission directly from the copyright holder. To view a copy of this licence, visit http://creativecommons.org/licenses/by/4.0/.

\section{References}

1. (2007) All-integrated Olympic stadium intelligent system. China Investigation \& Design 10(1):16-21

2. Zhang Y, Zhang YS (2013) Focal points in supervising building intelligent system. Adv Mater Res 739:532-536

3. Qian F, Yang L (2018) The green building environment of the gymnasium. Appl Mech Mater 878:202-209

4. Liang HT (2017) Development and design of intelligent stadium system based on Internet of Things. Electronic Design Engineering 25(15):35-38

5. Zhao JW, Tian L, Ding ZM et al (2014) Research on application of intelligent solar system in stadium. Applied Mechanics \& Materials 672-674:71-74

6. Jin RJ, Xiao YH (2013) Study on the glare problems of the intelligent lighting control system in modern stadiums. Adv Mater Res 753-755:1988-1991

7. Peng B, Fu Q, Chen L (2015) Performance-based design of smoke evacuation system and air supply system for large-sized indoor stadium. International Conference on Intelligent Computation Technology \& Automation. IEEE 524:65-68

8. Nishioka T, Ohtaka K, Hashimoto N et al (2000) Measurement and evaluation of the indoor thermal environment in a large domed stadium. Energy \& Buildings 32(2):217-223

9. Hu SB, Wang HJ, Xu DH (2008) Development of ticketing system for virtual gymnasium [J]. Experimental technology and management 25(2):101-103

10. Song Y (2014) Design of distributed support decision-making system model based on multi-agent technique for sporting event. International Conference on Intelligent Systems Design \& Engineering Applications 86:45-49
11. Han DY (2010) The development of the gymnasium game software. Advanced Display 21(5):137-138

12. Setko NP, Lozinskiĭ AS, Bulycheva EV (2012) Organization of medical and psycho-educational services for first-grader's under condition of gymnasium education secondary education. Gig Sanit 23(3):54-56

13. Li J, Zhang LY, Feng XJ, Jia KK, Kong FB (2019) Feature extraction and area identification of wireless channel in mobile communication. Journal of Internet Technology 20(2):547-555

14. Ross KE, Daniels L, Douglas HM (1980) The obese child: observations in the gymnasium of the Adelaide Children's Hospital. Med J Aust 2(2):80-84

15. Zhang Y, Wu X, Zhang J et al (2017) Study on the design schemes of the air-conditioning system in a gymnasium. IOP Conference Series Earth and Environmental Science 54(3):81-89

16. Hou W, Ning Z, Lei G et al (2018) Service degradability supported by forecasting system in optical data center networks. IEEE Syst J 99:1-12

17. Kani JI, Yoshino M, Tanaka T et al (2018) Flexible access system architecture to support diverse requirements and agile service creation. European Conference on Optical Communication 22(10):8790

18. Blackburn C, Harding A, Moreno-Cruz J (2017) Toward deepdecarbonization: an energy-service system framework. Current Sustainable/renewable Energy Reports 4(4):181-190

19. Flourentzou F, Pantet S, Ritz K (2017) Design and performance of controlled natural ventilation in school gymnasiums. Int J Vent 16(2):112-123

20. Giesinger J (2017) Educational justice, segregated schooling and vocational education. Theory \& Research in Education 15(1):88 102

21. Lin C, Li G, Shan Z et al (2017) Thinking and modeling for big data from the perspective of the I Ching. International Journal of Information Technology \& Decision Making $6(11): 1-13$

22. Rabl T, Gómez-Villamor S, Sadoghi M et al (2012) Solving big data challenges for enterprise application performance management. Proceedings of the Vldb Endowment 5(12): $1724-1735$

23. Rm VDS, Berger MA, Bregman DJ et al (2016) From big data to rich data: the key features of athlete wheelchair mobility performance. J Biomech 49(14):3340-3346

24. Qi J, Yang P, Hanneghan M et al (2018) A hybrid hierarchical framework for gym physical activity recognition and measurement using wearable sensors. IEEE Internet Things J 99:1-1

25. Pfeifer R, Iida F, Bongard J (2005) New robotics: design principles for intelligent systems. Artificial Life 11(1-2):99

26. Zhou Y, Ma X, Xing Z (2011) Preliminary analysis of the application of intelligent lighting control technology in gym. Process Automation Instrumentation 32(3):41-45

27. Haspel RL, Driscoll A, Kurbaj H et al (2016) The antibody identification card in action. Transfusion 55(11):2551-2551

28. Li Z, Fei RY, Tao T et al (2017) Handoff performance improvements in an integrated train-ground communication system based on wireless network virtualization. IEEE Trans Intell Transp Syst 99:1-14

29. Cecchi F, Sgandurra G, Mihelj M et al (2016) CareToy: an intelligent baby gym for intervention at home in infants at risk for neurodevelopmental disorders. IEEE Robotics \& Automation Magazine 23(4):1-1

30. Cortes C, Vapnik V (1995) Support-vector networks. Mach Learn 20(3):273-297

31. Zhou X, Jiang P, Wang X (2018) Recognition of control chart patterns using fuzzy SVM with a hybrid kernel function. J Intell Manuf 12:1-17 
32. Ebrahimi MA, Khoshtaghaza MH, Minaei S et al (2017) Visionbased pest detection based on SVM classification method. Computers \& Electronics in Agriculture 137(C):52-58

33. Wu H, Yu Y, Fu H, Zhang L (2017) On the prediction of chemical exergy of organic substances using least square support vector machine. Energy Sources Part A-Recovery Utilization and Environmenta Effects 39:2210-2215

34. Wu J, Wei W, Zhang L, Wang J, Damaševičius R, Li J, Wang H, Wang G, Zhang X, Yuan J, Woźniak M (2019) Risk assessment of hypertension in steel workers based on LVQ and fisher-SVM deep excavation. IEEE Access 7(1):23109-23119

35. Yang A, Yang X, Wu W, Liu H, Zhuansun Y (2019) Research on feature extraction of tumor image based on convolutional neural network. IEEE Access 7(1):24204-24213
36. Zhao L, Kang L, Yao S (2019) Research and application of acoustic emission signal processing technology. IEEE Access 7:984-993

37. Li Z, Zhao X (2017) BP artificial neural network based wave front correction for sensor-less free space optics communication. Opt Commun 385:219-228

38. Sun GL, Gebrekidanr ZT et al (2019) Dynamic reservation and deep reinforcement learning based autonomous resource slicing for virtualized radio access networks. Ieee Access 7: $45758-45772$

Publisher's note Springer Nature remains neutral with regard to jurisdictional claims in published maps and institutional affiliations. 